\title{
Increasing body satisfaction of body concerned women through evaluative conditioning using social stimuli
}

Citation for published version (APA):

Martijn, C., Vanderlinden, M., Roefs, A. J., Huijding, J., \& Jansen, A. T. M. (2010). Increasing body satisfaction of body concerned women through evaluative conditioning using social stimuli. Health Psychology, 29(5), 514-520. https://doi.org/10.1037/a0020770

Document status and date:

Published: 01/09/2010

DOI:

10.1037/a0020770

Document Version:

Publisher's PDF, also known as Version of record

Document license:

Taverne

Please check the document version of this publication:

- A submitted manuscript is the version of the article upon submission and before peer-review. There can be important differences between the submitted version and the official published version of record.

People interested in the research are advised to contact the author for the final version of the publication, or visit the DOI to the publisher's website.

- The final author version and the galley proof are versions of the publication after peer review.

- The final published version features the final layout of the paper including the volume, issue and page numbers.

Link to publication

\footnotetext{
General rights rights.

- You may freely distribute the URL identifying the publication in the public portal. please follow below link for the End User Agreement:

www.umlib.nl/taverne-license

Take down policy

If you believe that this document breaches copyright please contact us at:

repository@maastrichtuniversity.nl

providing details and we will investigate your claim.
}

Copyright and moral rights for the publications made accessible in the public portal are retained by the authors and/or other copyright owners and it is a condition of accessing publications that users recognise and abide by the legal requirements associated with these

- Users may download and print one copy of any publication from the public portal for the purpose of private study or research.

- You may not further distribute the material or use it for any profit-making activity or commercial gain

If the publication is distributed under the terms of Article $25 \mathrm{fa}$ of the Dutch Copyright Act, indicated by the "Taverne" license above, 


\title{
Increasing Body Satisfaction of Body Concerned Women Through Evaluative Conditioning Using Social Stimuli
}

\author{
Carolien Martijn, Marlies Vanderlinden, and \\ Anne Roefs \\ Maastricht University
}

\author{
Jorg Huijding \\ Erasmus University Rotterdam
}

\author{
Anita Jansen \\ Maastricht University
}

\begin{abstract}
Objective: Many women show weight and body concerns that leave them vulnerable to body dissatisfaction, lowered self-esteem, psychological distress, and eating disorders. This study tested whether body satisfaction could be increased by means of evaluative conditioning. Design: In the experimental condition $(n=26)$, women with low and high body concern completed a conditioning procedure in which pictures of their bodies were selectively linked to positive social stimuli (pictures of smiling faces). Pictures of control bodies were linked to neutral or negative social stimuli (neutral and frowning faces). In a control condition $(n=28)$, low and high body concerned women underwent a procedure in which pictures of their own body and of control bodies were randomly followed by positive, neutral, and negative social stimuli. Main Outcome Measures: Changes in body satisfaction and self-esteem before and after the conditioning task. Results: Women with high body concern demonstrated an increase in body satisfaction and global self-esteem when pictorial representations of their own bodies were associated with positive stimuli that signaled social acceptance. Conclusion: A simple conditioning procedure increased body satisfaction in healthy, normal weight women who were concerned about their shape and weight.
\end{abstract}

Keywords: body satisfaction, evaluative conditioning, social feedback, self-esteem

Physical appearance is a source of anxiety for many women in present society. Many studies have found that a majority of women are dissatisfied with their overall appearance and that a substantial number of women want to lose weight (e.g., Cash \& Henry, 1995; Cash, Morrow, Hrabovsky, \& Perry, 2004; Garner, 1997; Rodin, Silberstein, \& Striegel-Moore, 1984; Tiggemann, 2004). Other studies report that about $25 \%$ of adolescent girls with a normal weight/height ratio state that they are dissatisfied with their bodies, and a significant part of them show intense loathing of their bodies (e.g., Stice \& Whitenton, 2002). High body dissatisfaction may have serious consequences such as depression (Paxton, NeumarkSztainer, Hannan, \& Eisenberg, 2006), social anxiety (Cash \& Fleming, 2002a), and diminished quality of life (Cash \& Fleming, $2002 b$ ). Body dissatisfaction is a key factor underlying vulnera-

Carolien Martijn, Faculty of Psychology and Neuroscience, Department of Clinical Psychological Science, Maastricht University; Marlies Vanderlinden, Anne Roefs, and Anita Jansen, Department of Clinical Psychological Science, Maastricht University; and Jorg Huijding, Department of Clinical Psychology, Erasmus University Rotterdam.

We thank Ilonka van Rijn and Yvette Shaw for their help in preparing the manuscript.

Correspondence concerning this article should be addressed to Carolien Martijn, Faculty of Psychology and Neuroscience, Clinical Psychological Science, Maastricht University, P.O. Box 616, 6200 MD Maastricht, the Netherlands. E-mail: c.martijn@maastrichtuniversity.nl bility to, and maintenance of eating disorders and body dysmorphic disorders (e.g., Cooley \& Toray, 2001; Stice, 2002; Wilson, Fairburn, \& Agras, 1997). This study examines whether it is possible to improve body satisfaction of women who worry about their attractiveness.

When women specify what they dislike about their bodies, weight and size are the most frequently reported aspects. Other body aspects, such as height, hair, and face are mentioned much less often as a source of discontentment (Garner, 1997; see for an overview, Tiggemann, 2004). For most women, body weight is a central component of their self-esteem; it is not so much their overall appearance but their weight that they worry about (Patrick, Neighbors, \& Knee, 2004). Therefore, receiving negative feedback about body weight has severe negative consequences for one's feelings of self-worth (Clabaugh, Karpinsky, \& Griffin, 2008). Various speculations exist about the reasons why many women are dissatisfied with their bodies such as the increasing emphasis on thinness in Western standards of female beauty and the exposure to increasingly skinnier female models in the media (Groesz, Levine, \& Murnen, 2002; Stice, Maxfield, \& Wells, 2003; Weisbuch \& Ambady, 2009). As a result, women feel a constant pressure-tobe-thin, are prone to thin-ideal internalization and experience negative affect when they think they are not thin enough (Stice, Schupak-Neuberg, Shaw, \& Stein, 1995; Thompson \& Stice, 2001). Another cause of body dissatisfaction may stem from a misperception of the value that others attach to thinness. For example, body dissatisfied women think that men want thin women, thinner than men actually prefer. In contrast, most men 
have more accurate perceptions of what women find attractive about men's appearances (Bergstrom, Neighbors, \& Lewis, 2004; for similar findings see Fallon \& Rozin, 1985; Lamb, Jackson, Cassidy, \& Priest, 1993). Singh (1993) showed that men prefer women with a low but normal waist-to-hip ratio (WHR, ideal WHR is 0.7) rather than women with WHRs indicating extreme thinness. Singh explained this preference from an evolutionary perspective: a low to normal WHR indicates a better health and reproductive status.

Although numerous studies document the consequences, development, and maintenance of body dissatisfaction, there are few studies on how to reduce body dissatisfaction. Psychoeducational interventions often have little effect unless they are intensive and carefully targeted to participants' existing weight-related cognitions and behavior (see Stice, 2002; Stice, Marti, Spoor, \& Presnell, 2008). However, body dissatisfaction and anxiety were decreased in obese adults and adolescents by using specific mirror exposure interventions in a therapeutic setting (Hilbert, TuschenCaffier, \& Vögele, 2002; Jansen et al., 2008). When participants were trained to describe their bodies in a precise and neutral fashion when in front of a mirror, they de-emphasized negative evaluations such as "I am a fat nobody" (Jansen et al., 2008, p. 214). This decrease of body dissatisfaction was explained in terms of conditioning. When dissatisfied participants learned to think about their body without any negative associations, negative feelings in relation to their body such as disgust or anxiety reduced (Jansen et al., 2008, p. 217).

This study is a further exploration of the effect of conditioning on body dissatisfaction. Our main question is whether body satisfaction increases when women learn to associate their appearance with positive stimuli, especially when such stimuli signal social approval and acceptance. We believe that body (dis)satisfaction does not only rely on one's own evaluations but also depends on the perceived or anticipated approval of other people. We specifically tested whether an evaluative conditioning procedure in which pictures of participants' own bodies were consistently paired with positive stimuli in the form of accepting feedback of others (e.g., a smiling face) increases women's body satisfaction. The work of Baccus, Baldwin, and Packer (2004) on evaluative conditioning showed that selectively linking positive social stimuli to aspects related to the self (e.g., place of birth or first name) increased the automatic component of self-esteem (i.e., implicit self-esteem, Farnham, Greenwald, \& Banaji, 1999). We predicted that women with relatively high body concern would be especially sensitive to an induced association between their appearance and positive stimuli, and as a result would become more satisfied with their weight and body size.

\section{Method}

\section{Participants}

Fifty-seven female undergraduate students $(M$ age $=20.0$ years, $S D=1.45$ ) participated for course credit points and took part in the two sessions of the experiment. The standing ethical committee of the Faculty of Psychology and Neuroscience of Maastricht University, The Netherlands, approved the experiment. Participants were individually tested in two sessions with an interval of 8 days ( \pm 1 day).

\section{Procedure Session 1}

Each participant started with a series of questionnaires. The first questionnaire asked about "life satisfaction" and included target items about body satisfaction and current mood. We then administered the Rosenberg Self-Esteem Scale (RSES; Rosenberg, 1965) to assess global self-esteem, the State Self-Esteem Scale (SSES; Heatherton \& Polivy, 1991) to measure current self-esteem in three domains and the Eating Disorder Examination Questionnaire (EDE-Q; Fairburn \& Beglin, 1994).

Next, the female experimenter led the participant to an adjacent professional photo studio and requested her to change into standardized clothing. Tight-fitting short-sleeved tops and jazz pants were available in three different sizes; the experimenter estimated the appropriate size (size labels were removed to avoid a possible influence). Three standardized pictures were taken of the participant's body including the head against a white background: from the front, plus the left and the right lateral.

\section{Procedure Session 2}

Participants were randomly assigned to an experimental or control version of a conditioning task adapted from Baccus, Baldwin, and Packer (2004). A participant was seated at a computer and informed that pictures of her own body and bodies of other women would appear randomly in one of four quadrants of the computer screen. She was instructed to click on the picture as fast as possible and that by doing so another picture would be presented briefly (for $400 \mathrm{~ms}$ ) in that same quadrant. This procedure was repeated for 270 trials. The displayed body pictures were the three pictures that were taken of the participant during Session 1 and six preprogrammed pictures of two control persons (two young females of average height and weight, wearing the same top and pants as the participant, each photographed from the front, left and right lateral). To ensure that a participant would recognize the pictures of her own body, half of the participants were photographed in a pink top and the other half in a black top. When a participant was photographed in pink, the control women wore a black top and vice versa.

Consistent with the reinforcement schedule developed by Baccus, Baldwin, and Packer (2004), pictures of the own body in the experimental condition were always $(100 \%)$ followed by a picture of a smiling face ( 90 trials), whereas pictures of the control persons were followed by pictures of neutral $(50 \%)$ or frowning $(50 \%)$ faces (180 trials). In the control condition, a random selection of smiling, neutral or frowning faces followed the pictures of the participant's own body (90 trials) and the control persons (180 trials). The faces were selected from the NimStim Facial Stimuli Set $^{1}$ (Tottenham et al., 2009) and consisted of 25 female and 25 male faces. Figure 1 provides an illustration of the conditioning procedure.

After finishing the conditioning task, participants again completed the "life satisfaction" questionnaire, the RSES and the

\footnotetext{
${ }^{1}$ Development of the MacBrain Face Stimulus Set was overseen by Nim Tottenham and supported by the John D. and Catherine T. MacArthur Foundation Research Network on Early Experience and Brain Development. Please contact Nim Tottenham at tott0006@tc.umn.edu for more information concerning the stimulus set.
} 
a

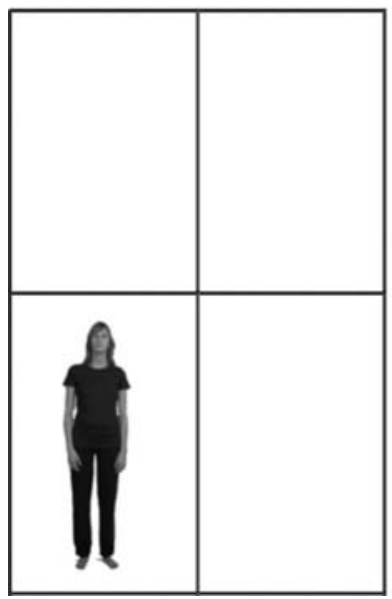

b

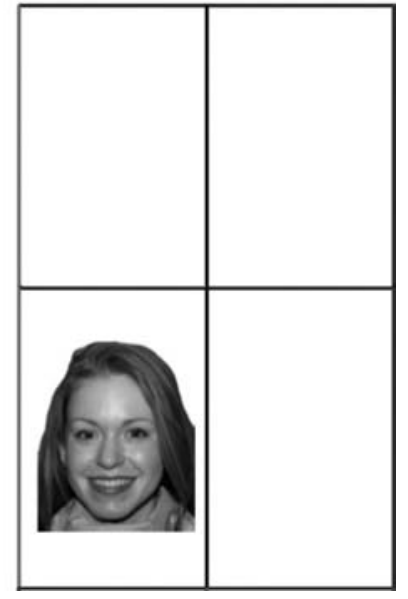

Figure 1. Example of the conditioning task. When a picture of a body (own or control) appeared in a quadrant of the screen (a), participants clicked on the picture with the computer mouse as quickly as possible. After the click, a photograph of a smiling, neutral, or frowning face (b) was shown for $400 \mathrm{~ms}$. The picture of the model in the right panel was adapted from the NimStim set of facial expressions (Tottenham et al., 2009).

SSES. We checked for contingency awareness by asking participants to indicate how many smiling, neutral or frowning faces followed their own pictures and the pictures of the other women. As a check for demand awareness, participants described the purpose of the study in their own words. Finally, participants were fully debriefed and asked for permission to use information about their body weight and height that had been gathered 3 weeks earlier in an annual mass testing session of all undergraduate psychology students. As a part of the testing session, all undergraduates were weighted and measured for future research purposes.

\section{Materials and Dependent Variables}

Current mood and body satisfaction. Questions about current mood and body satisfaction were included in a 13-item life satisfaction questionnaire (including eight filler items asking for satisfaction with their financial situation, study performance, etc.) to disguise our interest in participants' mood, body, and weight evaluations. Current mood was assessed by three items; "At this moment, my mood is cheerful/depressed/positive" rated at three $100 \mathrm{~mm}$ visual analogue scales (VAS; $0=$ not al all and $100=$ very much). The three mood items were highly correlated (after recoding of "depressed," Cronbach's $\alpha$ at Session 1 and Session 2 were .85 and .89 , respectively), and mean current mood measures for Session 1 and for Session 2 were computed.

Body satisfaction was assessed by two items on two $100 \mathrm{~mm}$ VAS; "at this moment I feel, $0=$ not at all satisfied with my body/weight $-100=$ very satisfied with my body/weight. Because the two items were highly correlated $(r=.79, p<.01$ at Session $1 ; r=.84, p<.01$ at Session 2), mean body satisfaction measures were calculated for Session 1 and Session $2 .^{2}$

RSES. The RSES consists of 10 items rated on 4-point Likert scales with the endpoints $1=$ strongly agree and $4=$ strongly disagree. After recoding of the negatively phrased items, the items scored at Session 1 were added to create a global self-esteem measure (Cronbach's $\alpha=.84$ ). Scores may vary from 10 to 40; higher scores indicate high global self-esteem. The same procedure was followed to construct a global self-esteem measure for Session 2 (Cronbach's $\alpha=.85$ ).

SSES. The SSES (Heatherton \& Polivy, 1991) consists of 20 items and aims to measure short-lived changes in self-esteem in three domains: performance (seven items, e.g., "I feel confident about my abilities"), social (seven items, e.g., "I feel concerned about the impression that I make") and appearance (six items, e.g., "I feel dissatisfied about my weight"). All items were rated on 5-point Likert scales with the endpoints $1=$ not al all and $5=$ extremely. After recoding the negatively phrased items, three state self-esteem subscales were created for each of the sessions by adding the relevant items per domain (Cronbach's $\alpha$ of SSESsubscales at Session 1 and Session 2 were all >.81). Higher scores indicate higher self-esteem.

EDE-Q. The EDE-Q is a self-report measure addressing eating disordered behavior and cognitions within a 28-day time frame (see Fairburn \& Beglin, 1994). The EDE-Q is a widely used and psychometrically sound self-report measure for the screening of eating disorders and body concern (Luce \& Crowther, 1999; Wilfley, Schwartz, Spurrell, \& Fairburn, 1997). Items of the EDE-Q load on one of four subscales: restraint eating (five items), eating concern (five items), shape concern (eight items), and weight concern (five items). Answers are gathered on 7-point scales ranging from $0=$ not at all to $6=$ highly frequent; higher scores indicate more psychopathology related to eating. The restraint subscale measures the intention to restrict or avoid food intake, for example, "Have you gone for long periods of time (8 waking hours or more) without eating anything at all to influence your shape or weight?" The eating concern subscale measures obsessive thoughts about calories and eating, such as, "Has thinking about food, eating or calories made it very difficult to concentrate on things you are interested in (e.g., working, following a conversation, or reading)?" The shape and weight subscales tap problematic preoccupation with body shape and weight and the importance of shape and weight for overall self-evaluation. Examples are: "Over the past 28 days, how uncomfortable have you felt seeing your body (e.g., seeing your shape in the mirror, in a shop window reflection, while undressing or taking a bath or shower)?", "Has your shape/weight influenced how you think (judge) yourself as a person?", or "How dissatisfied have you been with your shape/ weight?"

We assessed the EDE-Q at Session 1 only to distinguish between participants with relatively low and high concerns about shape and weight. Following the instructions of Fairburn and Beglin, subscale-scores were obtained by averaging the relevant

\footnotetext{
${ }^{2}$ An ANCOVA with Condition and Body Concern as between subject factors and body satisfaction at Session 1 as a covariate showed the same pattern of results. Body satisfaction at Session 1 was a significant covariate, $F(1,49)=84.92, p<.001, \eta_{\mathrm{p}}^{2}=.63$. We found the predicted effect of Condition (corrected for body satisfaction at Session 1) on body satisfaction at Session 2, $F(1,49)=5.98, p=.018, \eta_{\mathrm{p}}^{2}=.11$, and the predicted interaction of Condition and Body Concern, $F(1,49)=4.18, p<.05$, $\eta_{\mathrm{p}}^{2}=$ .08. The effect of Body Concern was nonsignificant, $F(1,49)=2.62$, $p=.12$.
} 
items ratings belonging to each subscale. The Cronbach's $\alpha$ of the restraint eating, and the eating, body shape, and weight concern subscales were $.84, .79, .91$, and .84 , respectively. A total EDE-Q scale was constructed by averaging the eating, restraint, shape, and weight subscales (Cronbach's $\alpha=.94$ ). The shape concern and the weight concern subscales of the EDE-Q were highly correlated, $r(54)=.85, p<.001$, and merged into one body concern scale (Cronbach's $\alpha=.94$ ). By means of a median split on the body concern scale (scores ranged from 0 to 4.28 , median $=1.70$ ), we distinguished a relatively low, and a relatively high body concerned group.

\section{Results}

\section{Awareness Check}

Data of three participants in the experimental condition were discarded because these participants showed awareness of the hypothesis and/or correctly detected that pictures of their own body were in $100 \%$ of the trials followed by smiling faces and the bodies of control women by neutral or frowning faces. As a result, the final sample consisted of 26 participants in the experimental condition and 28 in the control condition. As a further check on contingency awareness, the six estimates that participants had made about the percentages of smiling, neutral, and frowning faces that followed the pictures of their own body pictures and that of the control bodies were entered in a multivariate ANOVA. The overall difference between the experimental and control condition was nonsignificant, $F$ multivariate $(6,43)=2.01, p=.07$. On average, participants in the experimental condition estimated that the feedback scheme following their own body pictures consisted of $36.52 \%$ smiling faces, $29.72 \%$ neutral faces, and $33.32 \%$ frowning faces (SDs $22.50,10.81$, and $20.29 \%$ respectively). Thus, experimental participants did not detect that smiling faces always (100\%) followed their own body pictures and showed no contingency awareness. Control participants estimated that pictures of their own body were followed by $29.68 \%(S D=12.05)$ smiling faces, $32.28 \%(S D=15.77)$ neutral faces, and $38.28 \%(S D=16.28)$ frowning faces. These estimates matched the actual feedback scheme that showed each type of facial feedback in $33.3 \%$ of the own body picture trials.

\section{Participant Characteristics}

The mean body mass index (BMI, $\mathrm{kg} / \mathrm{m}^{2}$ ) for the total sample of participants was 22.17 ( $S D=1.35$, range: 19.1-24.3). A BMIindex between 19 and 25 reflects a normal body weight. A $2 \times 2$ (Condition [experimental, control condition] $\times$ (Body Concern [low, high]) ANOVA revealed no BMI differences between conditions (main effects and interaction effect, all $F s<1$ ).

To check for differences in eating disorder pathology, a similar ANOVA was conducted with the total EDE-Q score as dependent variable. High body concerned (BC) participants $(M=2.13, S D=$ .73) showed more eating pathology than low BC participants $(M=$ $.51, S D=.29), F(1,50)=109.8, p<.001, \eta^{2}=.67$. The main effect of Condition and the interaction of Condition and Body Concern were nonsignificant, $F s(1,50)<1$, ns. Hence, there were no a priori differences in eating pathology between the experimental and control condition. Total EDE-Q scores varied from 0 to
$3.70(M=1.34, S D=.99)$ indicating that none of the participants scored above the clinical significant $\geq 4.0$ cut-off score (Mond, Hay, Rodgers, \& Owen, 2006).

\section{Body Satisfaction}

We first checked whether at baseline, levels of body satisfaction were the same in the control condition and the experimental condition; there was no difference, $t(52)<1$. Next, body satisfaction scores were submitted to a $2 \times 2 \times 2$ (Time [body satisfaction at Session 1, body satisfaction at Session 2], Condition [experimental, control] $\times($ Body Concern [low, high] $)$ repeated measures ANOVA.

The first hypothesis was that body satisfaction would increase in the experimental condition where pictures of the own body were systematically followed by smiling faces. Body satisfaction would not be affected in the control condition where pictures of the own body pictures were randomly followed by smiling, neutral and frowning faces. The Time $\times$ Condition interaction confirmed our first prediction, $F(1,50)=6.60, p=.013, \eta_{\mathrm{p}}^{2}=.117$. In the experimental condition body satisfaction increased from Session 1 to Session $2, t(25)=2.61, p<.01, d=.35$. Body satisfaction remained the same in the control condition, $t(27)<1$.

The second hypothesis was that participants with high BC would be more perceptive to positive social feedback than participants with low BC. Thus, in the experimental condition, high BC participants were expected to show a greater increase in body satisfaction than low BC participants. The Time $\times$ Condition $\times$ Body Concern interaction provided evidence for the second prediction, $F(1,50)=5.00, p=.03, \eta_{\mathrm{p}}^{2}=.091$. In the experimental condition, only high $\mathrm{BC}$ participants showed a significant increase in body satisfaction, $t(13)=2.41, p<.05, d=.63$. Body satisfaction of low BC women did not change from Session 1 to Session 2, $t(13)=1.64, p=.13$. Body satisfaction of low BC women remained the same in both the experimental and the control condition, $t s(13)<1.5$, $n s$ (Figure 2 and Table 1 ). The two-way

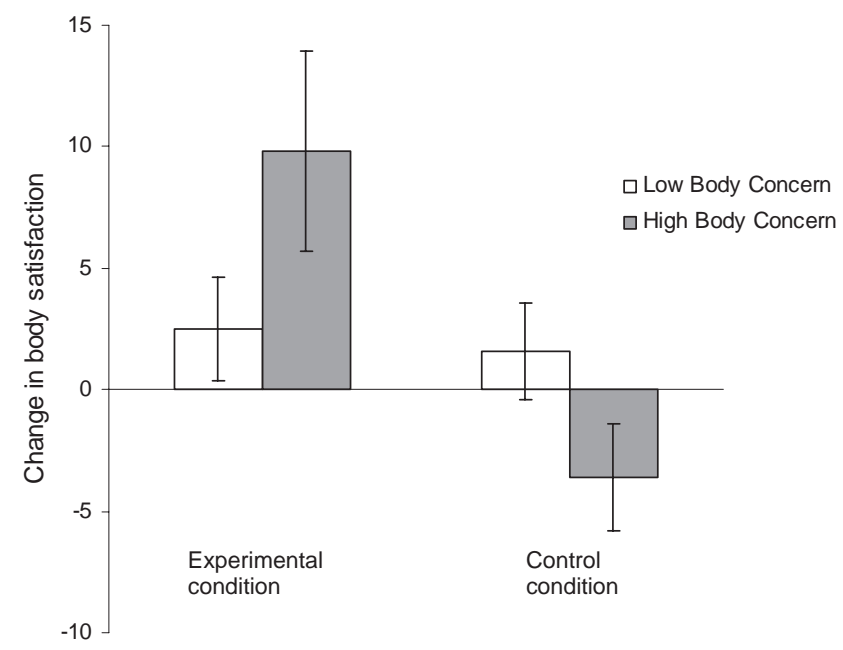

Figure 2. Change in body satisfaction as a function of Condition and Body Concern. Scores represent the mean difference scores $( \pm 1 S E)$ between body satisfaction at Session 1 and at Session 2. Higher scores indicate an increase in body satisfaction (measured on $100 \mathrm{~mm}$ VAS). 
Table 1

Body Satisfaction, RSES, SSES Subscales, and Mood in the Experimental and Control Condition at Session 1 and at Session 2

\begin{tabular}{|c|c|c|c|c|c|c|c|c|}
\hline & \multicolumn{4}{|c|}{ Experimental condition } & \multicolumn{4}{|c|}{ Control condition } \\
\hline & \multicolumn{2}{|c|}{ Low BC $(n=12)$} & \multicolumn{2}{|c|}{ High BC $(n=14)$} & \multicolumn{2}{|c|}{ Low BC $(n=14)$} & \multicolumn{2}{|c|}{ High BC $(n=14)$} \\
\hline & Session 1 & Session 2 & Session 1 & Session 2 & Session 1 & Session 2 & Session 1 & Session 2 \\
\hline Body satisfaction, $M(S D)$ & $67.6(14.9)$ & $70.1(12.1)$ & $42.1(17.0)$ & $52.0(14.2)$ & $67.4(15.1)$ & $68.9(15.4)$ & $49.5(18.9)$ & $45.9(17.8)$ \\
\hline RSES, $M(S D)$ & $32.8(3.8)$ & $32.7(3.6)$ & $31.2(3.2)$ & $32.3(3.1)$ & $33.1(3.1)$ & $33.4(4.1)$ & $29.4(4.6)$ & $29.2(4.2)$ \\
\hline SSES appearance, $M(S D)$ & $22.4(3.3)$ & $22.6(3.0)$ & $17.9(2.8)$ & $18.1(3.2)$ & $23.1(2.7)$ & $23.1(3.2)$ & $16.6(3.2)$ & $16.2(3.2)$ \\
\hline SSES social, $M(S D)$ & $27.8(4.3)$ & $28.5(4.1)$ & $25.4(3.6)$ & $25.6(3.7)$ & $30.5(3.4)$ & $30.4(2.9)$ & $24.8(4.7)$ & $24.7(4.2)$ \\
\hline SSES performance, $M(S D)$ & $27.5(3.4)$ & $28.3(3.5)$ & $25.8(4.3)$ & $26.9(4.1)$ & $28.1(2.7)$ & $28.1(2.6)$ & $24.0(5.5)$ & $24.4(5.2)$ \\
\hline Mood, $M(S D)$ & $64.4(14.0)$ & $58.9(15.2)$ & $62.3(14.7)$ & $57.8(15.1)$ & $69.9(11.1)$ & $66.1(15.1)$ & $56.8(16.2)$ & $53.6(20.6)$ \\
\hline
\end{tabular}

Note. Body Satisfaction Scale ranges from 0-100, RSES ranges from 10-40, SSES appearance subscale ranges from 6-42 social subscale from 7-49, SSES performance subscale from 7-49, Mood scale ranges from $0-100$.

interaction of Time and Body Concern was nonsignificant, $F(1$, $50)=.70, n s$

\section{RSES (Global Self-Esteem)}

RSES scores at Session 1 and at Session 2 were submitted to a mixed model Time $\times$ Condition $\times$ Body Concern repeated measure ANOVA. We did not expect changes in RSES because the scale intends to measure stable self-esteem that is invariant to momentary influences. A main effect of BC, $F(1,50)=6.85, p=$ $.012, \eta_{\mathrm{p}}^{2}=.12$, indicated that high $\mathrm{BC}$ had lower global selfesteem $(M=30.8, S D=3.9)$ than low BC participants $(M=33.3$, $S D=3.8)$ across sessions. Unexpectedly, we obtained an interaction of Time, Condition, and Body Concern, $F(1,50)=5.00, p=$ $.03, \eta_{\mathrm{p}}^{2}=.09$. Pairwise comparisons showed that global selfesteem increased in high $\mathrm{BC}$ women in the experimental condition, $t(13)=3.16, p=.008, d=.35$, and not in low BC women, $t(13)<1$, ns. In the control condition, there was no change in global self-esteem in high BC women or in low BC women, $t s<$ 1 (see Table 1 and Figure 3). All the other main and interaction effects were nonsignificant, $F s<1$, $n s$.

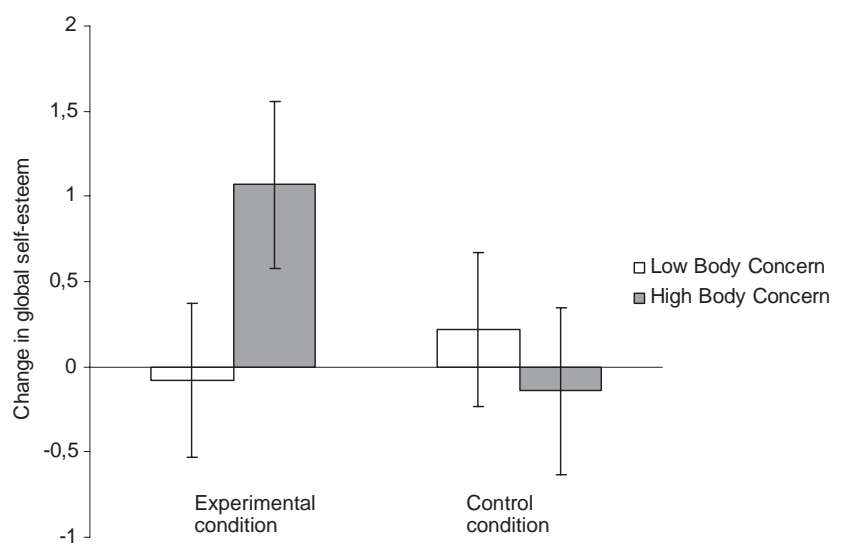

Figure 3. Change in RSES as a function of Condition and Body Concern. Scores represent the mean difference scores $( \pm 1 S E)$ between RSES at Session 1 and at Session 2. Higher scores indicate an increase in RSES (scale range 10 to 40 ).

\section{SSES and Mood}

To test for changes in mood and in the appearance, social and performance SSES from Session 1 to Session 2, we conducted four separate repeated measure Time $\times$ Condition $\times$ Body Concern ANOVAs. For appearance SSES, we obtained a main effect of Body Concern only, $F(1,50)=49.81, p<.001, \eta_{\mathrm{p}}^{2}=.50$. Across sessions, high BC participants had lower appearance SSES than low BC participants. For performance and social SSES, we found the same pattern of results. High BC participants had lower performance SSES than low BC participants, $F(1,50)=7.21, p=$ $.01, \eta_{\mathrm{p}}^{2}=.13$. High BC participants also had lower social SSES than low BC participants, $F(1,50)=17.33, p<.001, \eta_{\mathrm{p}}^{2}=.26$. All other main and interaction effects were nonsignificant, $F$ 's $<$ $1, n s$. With respect to mood, the ANOVA revealed no main or interaction effects, $F$ 's $<1.5, n s$.

\section{Discussion}

Female participants showed an increase in global self-esteem and satisfaction with their body shape and weight when pictures of their own body were systematically followed by evaluative positive stimuli in the form of smiling faces. These conditioning effects occurred only in women who expressed high concern about their weight and body before performing the conditioning task. Our results fit with earlier findings of Baccus et al. (2004) who found that pairing self-relevant stimuli (e.g., first name, date, and place of birth) with positive social stimuli produced an increase in selfesteem.

However, Baccus et al. (2004) observed conditioning effects derived exclusively from an implicit measure and not from explicit measures of self-esteem. Our experiment showed effects on explicit measures of body satisfaction and global self-esteem. A possible explanation for why we found effects on explicit measures could be that the content of our conditioning procedure was specifically and directly targeted at a vulnerable group and at a domain of self-esteem that causes anxiety for this group (weight and body shape). It is likely that how women evaluate their body, is highly influenced by their perceptions of how other people judge it. This fits well with the literature on contingencies of self-worth, which states that some individuals' self-esteem is highly dependent upon external validations such as the approval of and accep- 
tance of others (Crocker \& Wolfe, 2001). For women with high weight and $\mathrm{BC}$, repeated exposure to systematic associations of their own body and smiling faces may function as a sign that others approve of, and accept their physical appearance. This results in higher satisfaction with one's body and weight specifically and a rise in self-esteem in general. The conditioning procedure had no effect on women who expressed relatively little weight and $\mathrm{BC}$; this may be because their feelings of self-worth are not contingent upon body size or because they are not influenced by how others evaluate their shape and weight.

In some respects, the effects of conditioning on self-esteem are different from what we had expected. We measured both global self-esteem (RSES; Rosenberg, 1965) and state self-esteem (Heatherton \& Polivy, 2001); the first type is regarded as a stable, rather invariable condition, and the second as an indication of self-worth at a given moment, which may show variations in time. The reason why conditioning affected global self-esteem but not state self-esteem, in particular appearance self-esteem, is not immediately clear. A possible explanation for the lack of an effect on appearance self-esteem may be that some items of the appearance subscale do not specifically focus on bodily evaluations but more on a general impression ("I am worried about whether I am regarded as a success or a failure"). A reason for body concerned women's increase in global self-esteem may be that shape and weight evaluations played a central role in their sense of self-worth (Patrick, Neighbors, \& Knee, 2004). Forming positive associations with their body may have affected their general feelings of selfesteem. Other researchers have also reported that, while global self-esteem intends to measure a trait-like concept, RSES was sensitive to changes following therapeutic interventions (Agras, Walsh, Fairburn, Wilson, \& Kraemer, 2000; Korrelboom, De Jong, Huijbrechts, \& Daansen, 2009).

In this study, we used a type of conditioning that is probably best described as a form of evaluative conditioning (EC). The conditioning task aimed to establish an association between an unconditioned stimulus (US, the own body) and a conditioned stimulus (CS, smiling face). At a procedural level, EC is highly similar to Pavlovian conditioning (PC) but differs in terms of process. In PC, a CS is commonly nonevaluative in nature (such as a bell or light) and because PC is based on expectancy learning, participants should be contingency aware. In EC on the other hand, participants learn an association rather than an expectation. The effects of EC are believed to be highly resistant to extinction and changes in occasion setting. Moreover, participants do not have to be aware of the contingency between the US and CS (for a detailed discussion see De Houwer, Thomas, \& Baeyens, 2001). In the paradigm used in our study, the CS was evaluative in nature and conditioning effects occurred without participants being contingency aware. The study did not address the question whether the effects of EC on body dissatisfaction are durable and will occur under different circumstances. This remains an important issue for future research.

The current findings imply that problematic components of self-esteem may be altered by positive, accepting social feedback. Here feedback consisted of both male and female faces; future research should address whether the gender of a person giving feedback moderates the effects. Another question is whether social feedback is essential for the conditioning effects or if the same effects could be produced when representations of one's body are linked with nonsocial positive stimuli (e.g., roses, kittens, sunsets). As for now, our results suggest that a simple conditioning procedure is a useful method to increase body and weight satisfaction in a sample of healthy normal weight women without eating disorders, but who are body dissatisfied. It would be of value to examine whether conditioning procedures may lead to increased body satisfaction in a clinically diagnosed eating disordered population and thus be of use in clinical practice.

\section{References}

Agras, W. S., Walsh, B., Fairburn, C. G., Wilson, G. T., \& Kraemer, H. C. (2000). A multicenter comparison of cognitive-behavioral therapy and interpersonal psychotherapy for bulimia nervosa. Archives of General Psychiatry, 57, 459-466.

Baccus, J. R., Baldwin, M. W., \& Packer, D. J. (2004). Increasing implicit self-esteem through classical conditioning. Psychological Science, 15, 498-502. doi:10.1111/j.0956-7976.2004.00708.x

Bergstrom, R. L., Neighbors, C., \& Lewis, M. A. (2004). Do men find "bony" women attractive? Consequences of misperceiving opposite sex perceptions of attractive body image. Body Image, 1, 183-191. doi:10.1016/S1740-1445(03)00025-1

Cash, T. E., \& Henry, P. E. (1995). Women's body images: The results of a national survey in the U.S.A. Sex Roles, 33, 19-28. doi:10.1007/ BF01547933

Cash, T. F., \& Fleming, E. C. (2002a). Body image and social relations. In T. F. Cash \& T. Pruzinsky (Eds.), Body image: A handbook of theory, research, and clinical practice (pp. 277-286). New-York: Guilford Press.

Cash, T. F., \& Fleming, E. C. (2002b). The impact of body-image experiences: Development of the body image quality of life inventory. International Journal of Eating Disorders, 31, 455-460. doi:10.1002/ eat. 10033

Cash, T. F., Morrow, J. A., Hrabosky, J. I., \& Perry, A. A. (2006). How has body image changed? A cross-sectional investigation of college women and men from 1983 to 2001. Journal of Clinical Child and Adolescent Psychology, 35, 539-549. doi:10.1037/0022-006X.72.6.1081

Clabaugh, A., Karpinsky, A., \& Griffin, K. (2008). Body weight contingency of self-worth. Self and Identity, 7, 337-359. doi:10.1080/ 15298860701665032

Cooley, E., \& Toray, T. (2001). Body image and personality predictors of eating disorder symptoms during the college years. International Journal of Eating Disorders, 30, 28-36. doi:10.1002/eat.1051

Crocker, J., \& Wolfe, C. T. (2001). Contingences of self-worth. Psychological Review, 108, 593-623. doi:10.1037/0033-295X.108.3.593

De Houwer, J., Thomas, S., \& Bayens, F. (2001). Associative learning of likes and dislikes: A review of 25 years of research on human evaluative conditioning. Psychological Bulletin, 127, 853-869. doi:10.1037/00332909.127.6.853

Fairburn, C. G., \& Beglin, S. J. (1994). Assessment of eating disorders: Interview or self-report questionnaire? International Journal of Eating Disorders, 16, 363-370. doi:10.1002/1098-108X(199412)

Fallon, A. E., \& Rozin, P. (1985). Sex differences in perceptions of desirable body shape. Journal of Abnormal Psychology, 94, 102-105. doi:10.1037/0021-843X.94.1.102

Farnham, S. D., Greenwald, A. G., \& Banaji, M. R. (1999). Implicit self-esteem. In D. Abrams \& M. A. Hogg (Eds.), Social cognition and social identity (pp. 230-248). Oxford, England: Blackwell.

Garner, D. M. (1997). The 1997 body image survey results. Psychology Today, 30, 75-84. Retrieved from http://search.ebscohost.com/ login. aspx ?direct $=$ true $\& d b=$ buh $\& A N=9701294607 \&$ site $=$ ehost live \&scope $=$ site

Groesz, L. M., Levine, M. P., \& Murnen. (2002). The effect of experimental presentation of thin media images on body satisfaction: A meta- 
analytic review. International Journal of Eating Disorders, 31, 1-16. doi:10.1002/eat.10005

Heatherton, T. F., \& Polivy, J. (1991). Development and validation of a scale for measuring state self-esteem. Journal of Personality and Social Psychology, 60, 895-910. doi:10.1037/0022-3514.60.6.895

Hilbert, A., Tuschen-Caffier, B., \& Vögele, C. (2002). Effects of prolonged and repeated body image exposure in binge eating disorder. Journal of Psychosomatic Research, 52, 137-144. doi:10.1016/S0022-3999(01) 00314-2

Jansen, A., Bollen, D., Tuschen-Caffier, B., Roefs, A., Tanghe, A., \& Braet, C. (2008). Mirror exposure reduces body dissatisfaction and anxiety in obese adolescents: A pilot study. Appetite, 51, 214-217. doi:10.1016/j.appet.2008.01.01

Korrelboom, K., De Jong, M., Huijbrechts, J., \& Daansen, P. (2009). Competitive memory training (COMET) for treating low self-esteem in patients with eating disorders: A randomized clinical trial. Journal of Consulting and Clinical Psychology, 77, 974-980. doi:10.1037/ a0016742

Lamb, S. C., Jackson, L. A., Cassiday, P. B., \& Priest, D. J. (1993). Body figure preferences of men and women: A comparison of two generations. Sex Roles, 28, 345-358. doi:10.1007/BF00289890

Luce, K. H., \& Crowther, J. H. (1999). The reliability of the Eating Disorder Examination self-report questionnaire version (EDE-Q). International Journal of Eating Disorders, 25, 349-351. doi:10 $.1002 /$ (SICI) 1098-108X(199904)25:3 <349::AID-EAT15>3.0.CO;2-M

Mond, J. M., Hay, P. J., Rodgers, B., \& Owen, C. (2006). Eating disorder examination questionnaire (EDE-Q): Norms for young adult women. Behavioral Research and Therapy, 44, 53-62. doi:10.1016/ j.brat.2004.12.003

Patrick, H., Neighbors, C., \& Knee, C. R. (2004). Appearance-related social comparisons: The role of contingent self-esteem and selfperceptions of attractiveness. Personality and Social Psychology Bulletin, 30, 501-514. doi:10.1177/0146167203261891

Paxton, S. J., Neumark-Sztainer, D., Hannan, P. J., \& Eisenberg, M. E. (2006). Body dissatisfaction prospectively predicts depressive mood and low self-esteem in adolescent girls and boys. Journal of Clinical Child and Adolescent Psychology, 35, 539-549. doi:10.1207/ s15374424jccp3504_5

Rodin, J., Silberstein, L. R., \& Striegel-Moore, R. H. (1984). Women and weight: A normative discontent. In T. B. Sonderegger (Ed.), Nebraska Symposium on Motivation: Vol. 32. Psychology and gender (pp. 267307). Lincoln: University of Nebraska Press.

Rosenberg, M. (1965). Society and the adolescent self-image. Princeton, NJ: Princeton University Press.
Singh, D. (1993). Adaptive significance of female physical attractiveness: Role of waist-to-hip ratio. Journal of Personality and Social Psychology, 65, 293-307. doi:10.1037/0022-3514.65.2.293

Stice, E. (2002). Risk and maintenance factors for eating pathology: A meta-analytic review. Psychological Bulletin, 128, 825-848. doi: 10.1037//0033-2909.128.5.825

Stice, E., Marti, C. N., Spoor, S., \& Presnell, K. (2008). Dissonance and healthy weight eating disorder prevention programs: Long-term effects from a randomized efficacy trial. Journal of Consulting and Clinical Psychology, 76, 329-340. doi:10.1037/0022-006X.76.2.329

Stice, E., Maxfield, J., \& Wells, T. (2003). Adverse effects of social pressure to be thin on young women: An experimental investigation of the effects of "fat talk". International Journal of Eating Disorders, 34, 108-117. doi:10.1002/eat.10171

Stice, E., Schupak-Neuberg, E., Shaw, H. E., \& Stein, R. I. (1994). Relation of media exposure to eating disorder symptomatology: An examination of mediating mechanisms. Journal of Abnormal Psychology, 103, 836-840. doi:10.1037/0021-843X.103.4.836

Stice, E., \& Whitenton, K. (2002). Risk factors for body dissatisfaction in adolescent girls: A longitudinal investigation. Developmental Psychology, 38, 669-678. doi:10.1037//0012-1649.38.5.669

Thompson, J. K., \& Stice, E. (2001). Thin-ideal internalization: Mounting evidence for a new risk factor for body-image disturbance an eating pathology. Current Directions in Psychological Science, 10, 181-183. doi:10.1111/1467-8721.00144

Tiggemann, M. (2004). Body image across the adult life span: Stability and change. Body Image, 1, 29-41. doi:10.1016/S1740-1445(03)00002-0

Tottenham, N., Tanaka, J., Leon, A. C., McCarry, T., Nurse, M., Hare, T. A., .. Nelson, C. A. (2009). The NimStim set of facial expressions: Judgments from untrained research participants. Psychiatry Research, 168, 242-249. doi:10.1016/j.psychres.2008.05.006

Weisbuch, M., \& Ambady, N. (2009). Unspoken cultural influence: Exposure to and influence of nonverbal bias. Journal of Personality and Social Psychology, 96, 1104-1119. doi:10.1037/a0015642

Wilfley, D. E., Schwartz, M. B., Spurrell, E. B., \& Fairburn, C. G. (1997). Assessing specific psychopathology of binge eating disorder patients: Interview or self-report? Behaviour Research and Therapy, 35, 11511159. doi:10.1016/S0005-7967(97)80010-1

Wilson, G. T., Fairburn. G. C., \& Agras, W. S. (1997). Cognitivebehavioral therapy for bulimia-nervosa. In D. M. Garner \& P. E. Garfinkel (Eds.), Handbook of treatment for eating disorders. New York: Guilford Press. 